\title{
SEVILLA EN LA PRIMERA DÉCADA DEL SIGLO XXI: TRANSFORMACIONES URBANAS HACIA UN NUEVO MODELO DE CIUDAD
}

\author{
Manuel Jesús Marchena Gómez \\ Enrique Hernández Martínez \\ Departamento de Geografía Física y Análisis Geográfico Regional. \\ Universidad de Sevilla \\ mmarchena@us.es
}

\section{RESUMEN}

Este artículo ofrece una interpretación del proceso urbano contemporáneo de una ciudad, Sevilla, a partir del análisis de lo acontecido en la urbe en la primera década del siglo XXI. El caso de Sevilla es muy significativo y útil como caso-ejemplo de ciudad histórica capaz de optar a transformaciones urbanas y cambios en sistemas urbanos importantes como el espacio público o la movilidad, y las tensiones y contradicciones que dichos procesos suelen conllevar, y también de la posibilidad de encontrar caminos para actualizar las funciones de la ciudad a los nuevos retos sociales, económicos y políticos en los que la situación de fuerte crisis actual está situando a muchas ciudades.

Palabras clave: Sevilla, desarrollo urbano, plan general, peatonalización, proyectos urbanos, modelo de ciudad.

\section{ABSTRACT}

This paper offers an interpretation of the contemporary urban process of a city, Seville, from the analysis of what happened in the city in the first decade of the century. The case of Seville is very significant and useful as case-example of historic city able to make urban transformations and changes in major urban systems, as public space and mobility, and

Fecha de recepción: abril 2014.

Fecha de aceptación: diciembre 2014. 
the tensions and contradictions that often accompany these processes, and also the ability to find ways to upgrade the functions of the city to the new social, economic and political challenges that the situation of strong current crisis is placing many cities.

Keywords: Seville, urban development, general plan, pedestrianization, urban projects, city model.

\section{INTRODUCCIÓN}

Durante la primera década del siglo XXI, Sevilla conoció un fuerte impulso de las inversiones públicas y privadas ${ }^{1}$, traducidas en numerosos proyectos infraestructurales, urbanísticos y económicos que, bajo la dirección del nuevo Plan General de Urbanismo (2006), dieron lugar a una notable transformación urbana que conviene analizar con detenimiento.

Figura 1

SEVILLA Y SU ÁREA METROPOLITANA EN EL SISTEMA DE CIUDADES DE LA PENÍNSULA IBÉRICA

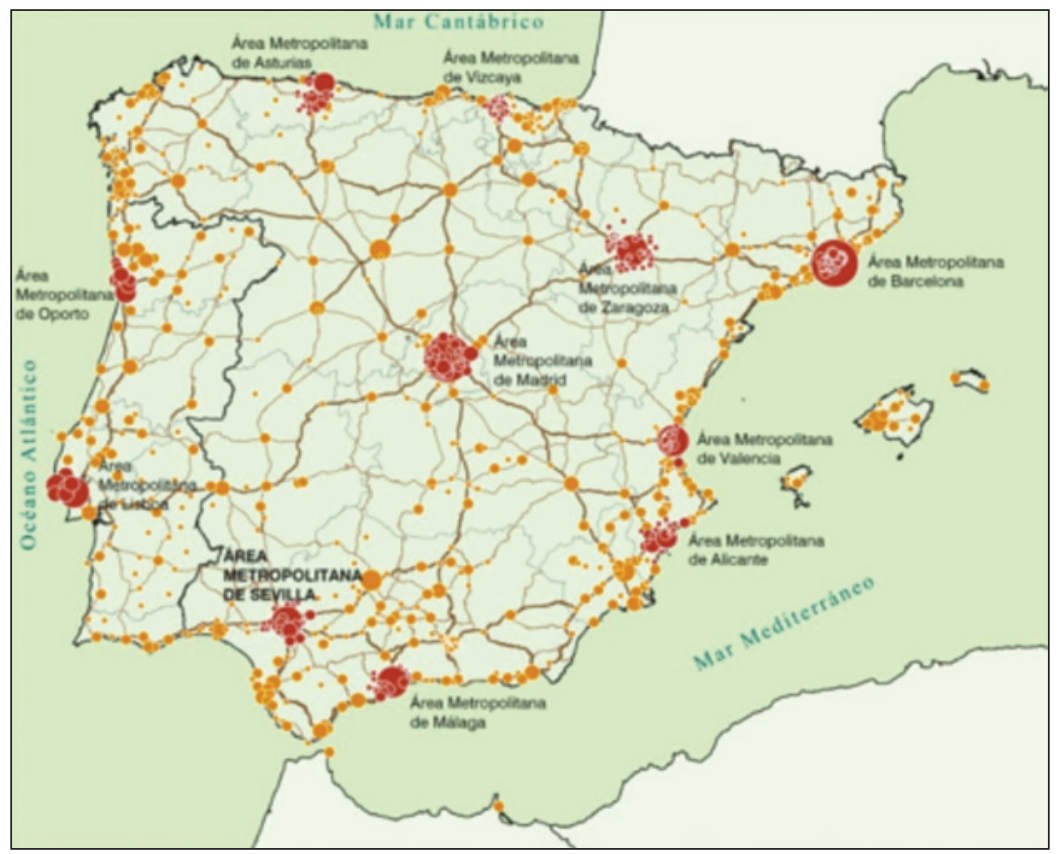

Fuente: Atlas Sevilla Metropolitana. Sevilla Global (Ayuntamiento de Sevilla).

1 La licitación oficial en construcción en la provincia de Sevilla pasó de 2.239 millones de euros en el período 1993-2000, a 7.476 millones de euros en el 2001-2008 (fuente: Instituto de Estadística y Cartografía de Andalucía. Indicadores Estadísticos de Andalucía). La inversión en todos los sectores económicos pasó de 103.606 mill. de $€$ en el período 1991-1998, a 448.752 en el 2001-2008, en el municipio de Sevilla (fuente: Consejería de Economía, Innovación y Ciencia, a partir de la tabla Inversiones según sector económico en el Registro Industrial). 
Acciones en pro del espacio público (peatonalizaciones en el centro histórico), proyectos para una nueva movilidad, con nuevos transportes públicos (metro, tranvía) y la apuesta por la bicicleta (carril bici, sistema de alquiler), desarrollos industriales muy determinados (nuevas factorías de Heineken-Cruzcampo, Airbus, Abengoa, ampliación de Renault, ampliación del puerto), a la vez que ejemplos de arquitectura de autor («setas» de la Encarnación), o el nuevo (y único) rascacielos de la ciudad (torre de César Pelli). La pregunta fundamental que conviene hacerse es si el catálogo de elementos que conforman ese proceso urbano son parte de un modelo de ciudad conscientemente constituido, y cuáles son los aspectos en que ese modelo se fundamenta y avanza, y cuáles las incoherencias y contradicciones internas que pudieran surgir.

La segunda cuestión clave que deberíamos de plantearnos en tiempos de crisis económica y ausencia casi total de inversiones, es hasta qué punto las ciudades pueden prolongar en el tiempo la rentabilización de esos proyectos renovadores. La capacidad de una respuesta creativa por parte del establecimiento institucional y político, y de una movilización constructiva por parte de la ciudadanía serían los factores críticos para intentar emerger un nuevo modelo de ciudad con visos de futuro.

\section{SEVILLA EN LA SEGUNDA MITAD DEL SIGLO XX: DEL DESARROLLISMO ESPECULATIVO A LA EXPOSICIÓN UNIVERSAL DE 1992}

Tras una larga post-guerra, a partir de finales de los 50 y los 60, la ciudad se había convertido en polo de atracción de la emigración campesina andaluza. Entre 1961 y 1965 se produce el mayor crecimiento demográfico de la historia de Sevilla, aumentando la población en 106.245 habitantes. A la ciudad llegan amplios contingentes de población que van pasando paulatinamente de vivir en núcleos de autoconstrucción precaria (chabolas) a nuevos barrios de bloques construidos por iniciativa pública (Melero Ochoa, 2005). De manera simultánea, las poblaciones de clase obrera originarias de barrios del casco antiguo y los arrabales históricos como Triana fueron siendo expulsadas por la presión especulativa del mercado inmobiliario hacia esas nuevas barriadas del extrarradio. La ciudad histórica sufrió un profundo proceso de degradación y destrucción física de numerosos edificios del caserío tradicional (muchas casas-palacio) de gran interés patrimonial. Concretamente, de los 684 edificios civiles catalogados como relevantes en 1951, el 25\% fueron derribados antes 1984, y un 5\% más hasta 1998 (Collantes de Terán y Gómez, 1999). Por parte del estado se ponen en marcha proyectos de creación de tejido industrial (polígonos y polos industriales), insuficientes y en buena parte fallidos.

La evolución de la ciudad en las tres últimas décadas del siglo XX está marcada por dos hechos de amplio recorrido urbano y socioeconómico: la conversión en capital administrativa y política de la nueva comunidad autónoma de Andalucía, y la celebración de la Exposición Universal de 1992.

En 1975 Sevilla es una capital provincial con 600.000 habitantes, a la cabeza de la región más pobre del país, y sin un papel especialmente significativo en la escena nacional. Sin embargo, la transición desencadenó una serie de profundos procesos políticos y administrativos, incluyendo la descentralización regional que convirtió a Sevilla en la capital de la región más poblada, y la segunda en extensión de todas las nuevas comunidades autónomas (Carrillo Benito, 1997). 
Figura 2

DESAHUCIO DE VECINOS DEL BARRIO HISTÓRICO DE TRIANA, FINALES DE LOS AÑOS 60

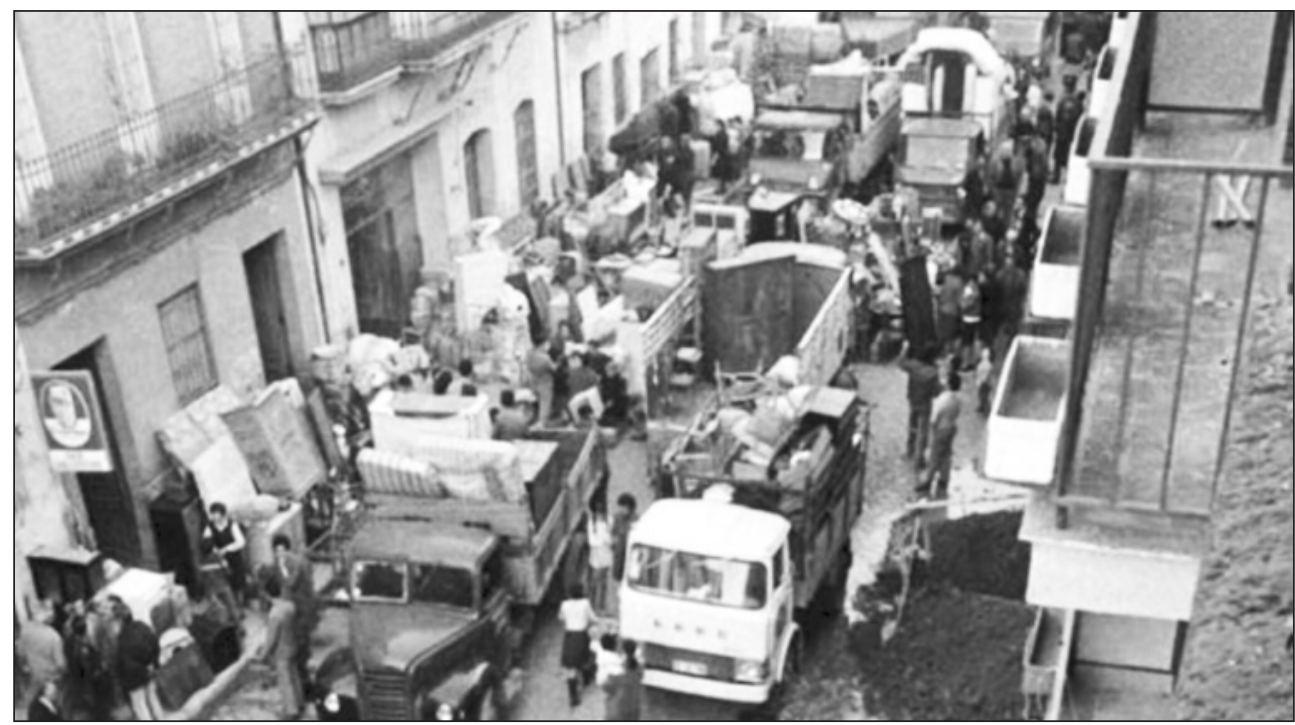

Fuente: ICAS-SAHP, Fototeca Municipal de Sevilla, archivo Serrano.

Figura 3

EVOLUCIÓN DE SEVILLA Y SU ÁREA METROPOLITANA DURANTE EL SIGLO XX

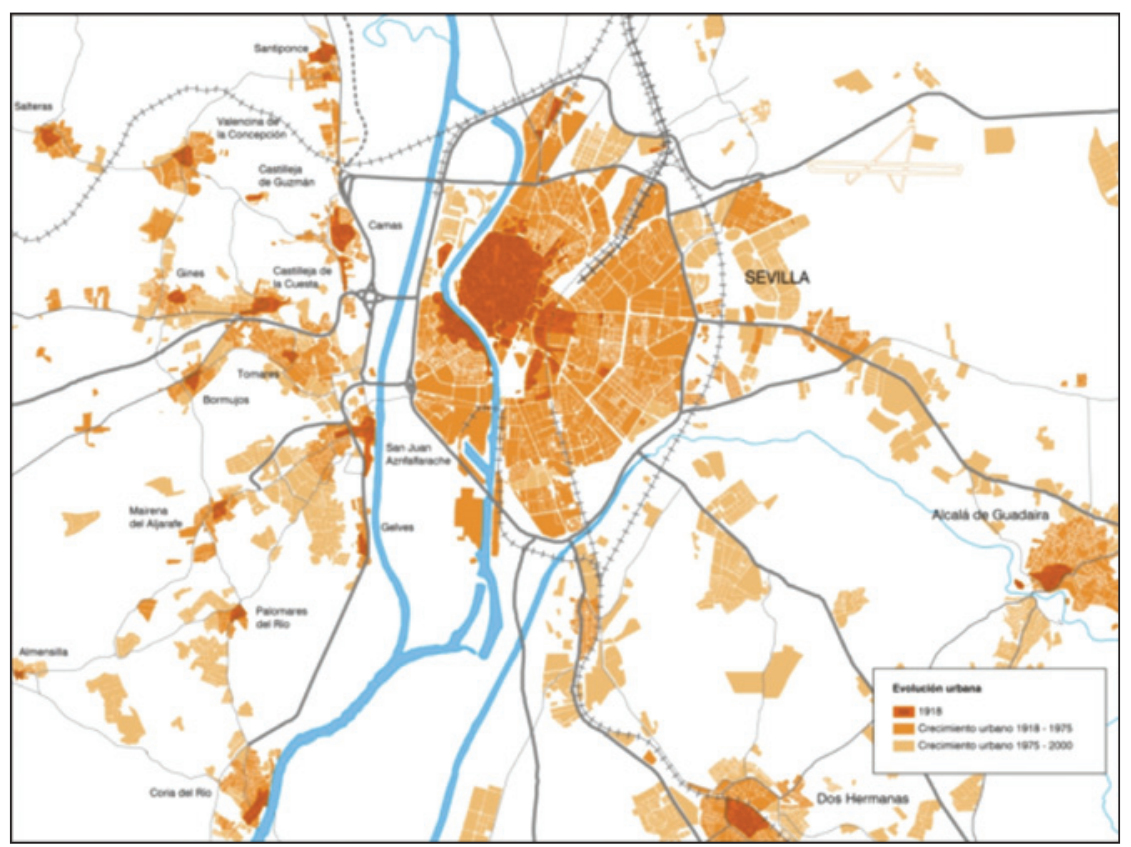

Fuente: Atlas Sevilla Metropolitana. Sevilla Global (Ayuntamiento de Sevilla). 
La creación ex-novo de la nueva administración pública regional, con sus necesidades de sedes y espacios, una nueva clase política, y el aumento de la importancia del sector público en la economía local, han sido muy importantes en la configuración de la ciudad de hoy. Políticamente aumentó la relevancia y proyección exterior de la ciudad, con un re-adquirido papel en la escena nacional. Habida cuenta, además, del peso político de Andalucía y especialmente de Sevilla dentro del Partido Socialista Obrero Español, gobernante en prácticamente todas las instancias de poder en buena parte de los 80 y 90.

\section{II.1. Expo'92, la gran transformación urbana}

La ciudad se convirtió en sede de una nueva administración que reclamaba del estado central medidas de reequilibrio territorial para la región más pobre y atrasada de España, y se encontró al frente de un proyecto de estado, como fue la celebración de la Exposición Universal de 1992.

La incidencia de este evento en la morfología urbana fue intensa (Pérez Escolano, 1998). Sobre todo por el enorme flujo de inversiones, en torno a los 6.000 millones de euros, de los cuales el $90 \%$ se destinó a obras de infraestructuras fuera del propio recinto expositivo (Álvarez Rey, 2000).

Desde 1979, el acometimiento de políticas urbanísticas de raíz democrática por los primeros ayuntamientos salidos de las elecciones, había llevado en primer lugar a la aplicación urgente de un urbanismo «defensivo» y «paliativo», mediante normativas y acciones que pusieran fin a la intensa destrucción del patrimonio arquitectónico del casco histórico de las décadas anteriores, a la vez que intentaba dotar de equipamientos y servicios esenciales a la enorme cantidad de barrios periféricos que carecían de colegios, asistencia sanitaria, transportes, y en muchos casos incluso pavimento (Cantero Martín y otros, 1999).

El nuevo Plan General de Ordenación Urbanística de 1986 planteó por primera vez el equilibrio entre el centro y la periferia de la ciudad, la forma general y la recomposición de la trama urbana, y también la protección integral del centro histórico como elemento valioso a conservar en su conjunto, más allá de los edificios patrimoniales concretos (Lerdo de Tejada, 2004). Con el horizonte de la celebración de 1992, estos objetivos se cumplieron en tiempo record. Las nuevas vías de circunvalación, la eliminación de las «cicatrices» y vacíos urbanos causados por las vías férreas, la apertura al río, la incorporación de espacios degradados al tejido urbano. Además, la planificación de la ciudad hubo de incorporar forzosamente el diseño del recinto de la Exposición, concebido como un proyecto de Estado, diseñado y ejecutado desde instancias gubernamentales externas a la ciudad, y que por eso mismo presenta aún hoy, dificultades de integración en la trama urbana de Sevilla (Pérez Escolano, 1998).

Se construyeron un nuevo aeropuerto, nuevos espacios culturales, como el Teatro de la Maestranza o el Teatro Central, una nueva estación de ferrocarril, a la que llegaría la primera línea de alta velocidad construida en España: Madrid-Sevilla (hasta once años después no se inauguraría la siguiente, Madrid-Zaragoza), 6 nuevos puentes sobre el río Guadalquivir, nuevas vías rápidas de circunvalación y avenidas de conexión interior de la ciudad. Se reabrió la lámina fluvial colindante al centro histórico (había sido cegada a mitad del siglo XX como 
defensa a las inundaciones), y se produjo un aumento cuantitativo y cualitativo de la oferta hotelera de la ciudad. Todo ello supuso una profunda transformación y modernización en el escenario urbano de Sevilla.

El recinto donde se celebró la Exposición de 1992 (Expo'92), la llamada «isla» de la Cartuja, era un territorio que había sido objeto de polémicas urbanas en los años de la transición al despertar tensiones inmobiliarias especulativas, que quedarían finalmente resueltas al ser mantenido como suelo público destinado a este proyecto. La celebración de la exposición fue un éxito de público, con 41 millones de visitas (una de las exposiciones universales más visitadas de la historia) (Pablo-Romero, 2002), y un éxito organizativo que, junto a las Olimpiadas de Barcelona'92, fueron la mejor campaña de imagen de un país, España, que había estrenado democracia recientemente, que se incorporaba a la entonces Comunidad Económica Europea, y cuyas perspectivas económicas empezaban a mejorar sustancialmente.

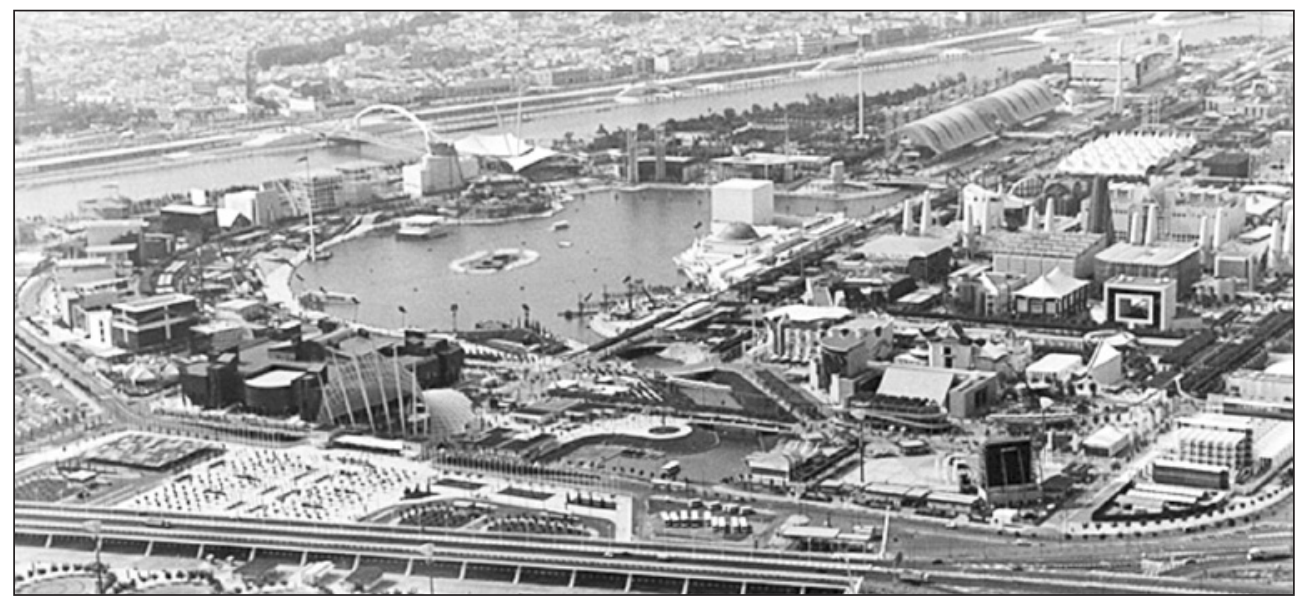

Foto: García Cordero.

Los años de construcción de la Expo'92 supusieron un aumento del empleo y una mejora de la tasa de convergencia económica con el resto del país (Fig. 5), pasando del 70'5\% en 1984 al 80\% en 1992. Al crecimiento de la Universidad de Sevilla en alumnos y especialidades, y la mejora y modernización de la oferta cultural de la ciudad que ya venía ocurriendo en esta época, se unió el cosmopolitismo y apertura al exterior promovida durante los seis meses que duró la celebración de la exposición universal. Todo ello supuso sin duda un cambio en la perspectiva y forma de entender la propia cultura y la propia ciudad de buena parte de la sociedad local.

Bien es cierto que durante las fases de construcción y preparación de la Expo'92, importantes medios de opinión y sectores políticos y sociales más tradicionalistas de la sociedad local, desarrollaron una crítica a la generalidad del proyecto. La falta de liderazgo local en el 
mismo y el peso preponderante del gobierno central en su planificación y financiación contribuyeron también, ciertamente, a que la población local viviera en parte como algo ajeno el evento que se estaba gestando, hasta que se abrieron las puertas del mismo. Una vez iniciada la Expo'92, el soporte y la adhesión de la población local al mismo fue muy mayoritario, y ha quedado ya marcado en la memoria colectiva como una «época dorada» de la ciudad.

Figura 5

PIB PER CÁPITA. RATIO SEVILLA/ESPAÑA. 1980-1992

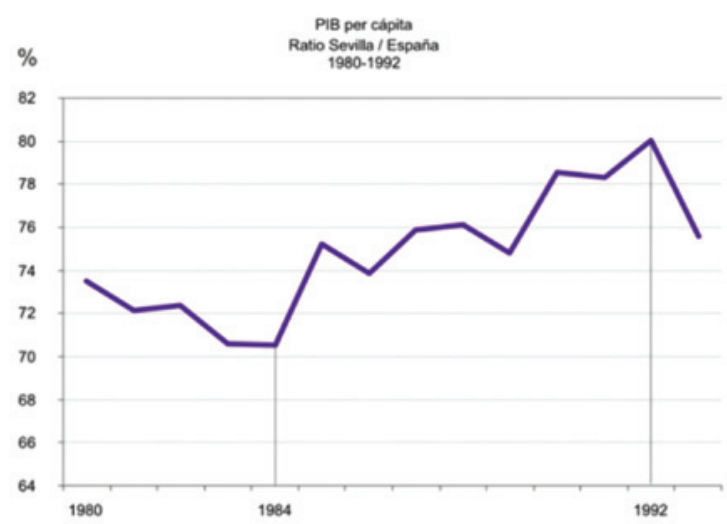

Fuente: INE y elaboración propia.

\section{II.2. Después de la Expo: el agotamiento de un modelo}

Tras la conclusión del evento expositivo, la ciudad se ve abocada a una etapa de estancamiento y depresión, común a muchas urbes que han realizado un gran esfuerzo socioeconómico centrado en un proyecto concreto, a la conclusión del mismo.

Esta depresión post-expo fue especialmente dura ya que el cierre de la Exposición, octubre de 1992, coincidió exactamente con el inicio de la importante crisis económica que sufrió el país entre el último trimestre de 1992 y 1995. En este contexto se redujeron las visitas turísticas, el empleo, y la inversión pública dejó de fluir. A ello se unía la debilidad política del reciente gobierno local de coalición entre el Partido Popular y el Partido Andalucista, y un tejido social y económico que se demostró insuficientemente preparado para asumir el liderazgo de la propia ciudad y continuar por un camino de progreso sostenido. La diferencia con lo ocurrido en Barcelona era evidente. Allí, a partir de 1987 se había iniciado la elaboración de un Plan Estratégico pensado desde las Olimpiadas pero proyectando su alcance mucho más allá, es decir, estableciendo los escenarios de futuros que rentabilizarían y proyectarían los beneficios del evento más allá de 1992. Y ello desde el liderazgo local y la anuencia de los sectores más dinámicos de la urbe. En Sevilla la situación fue distinta, no sólo no se había desarrollado una reflexión de fondo sobre la ciudad post-expo (cuando además propuestas urbanísticas del plan general prácticamente se habían completado en 1992), sino incluso el uso del recinto estaba sometido a dudas. El proyecto de convertir la mayor parte del mismo en un Parque Científico y Tecnológico 
acusó el exceso de optimismo en la «venta» política del mismo como si se tratara de un proyecto a corto plazo, cuando la realidad ha demostrado que era a medio y largo plazo.

No es de extrañar, por tanto, que la opinión pública local hubiera asumido que el desarrollo urbano de Sevilla estaba necesariamente vinculado a eventos externos, como las Exposiciones de 1929 y 1992 que habían transformado profundamente la ciudad, ejerciendo el denominado «efecto pulsar» (Vegara, A. 2004). Sevilla es una ciudad muy habituada al «evento», ya que su calendario anual marcado por dos acontecimientos de masas que definen muchos aspectos económicos, sociales y urbanísticos de la ciudad, como son la celebración de la Semana Santa y la Feria de Abril.

A finales de la década el modelo urbano-territorial de la ciudad parece agotado. En los últimos años, además, la falta de interés político por renovar la planificación urbanística, propició el desarrollo de importantes operaciones inmobiliarias planificadas «ad hoc» dentro de la más pura ortodoxia especulativa, como la operación de «Uralita», por ejemplo, que en 1998 produjo el desmantelamiento de una factoría de material de construcción y el cambio de la calificación del suelo de industrial en residencial, otorgando gigantescos beneficios a sus propietarios, mientras la ciudad veía reducirse su tejido industrial.

\section{EL SIGLO XXI. DESARROLLO DE UN NUEVO MODELO DE CIUDAD}

A principios de este siglo, se pone en marcha la redacción de un nuevo Plan General de Ordenación Urbanística (PGOU), a raíz del cambio político en el gobierno de la ciudad formado por una coalición de nuevo con el Partido Andalucista como bisagra, ahora en una doble coalición con el PSOE: en el Ayuntamiento de Sevilla y en la Junta de Andalucía.

Una de las características del nuevo PGOU fue su vocación de servir de guía y referencia absoluta para el urbanismo de la ciudad, dada la necesidad imperiosa de cubrir el vacío de modelo que venía detectándose desde varios años atrás. En este momento, el prestigio de la idea de confiar el desarrollo de la ciudad a la excepcionalidad de un evento exterior se había prácticamente extinguido y resurge la necesidad de realizar una planificación endógena. Por ello, el proceso de redacción se desarrolla en un ambiente de mayor participación, sobre todo de los sectores académicos, organizaciones ciudadanas y agentes sociales. Esto supone una verdadera novedad, a la que se une de manera paralela la elaboración del Plan Estratégico Sevilla 2010. (Ayuntamiento de Sevilla, 2003) Ambos procesos de reflexión y planificación, simultáneos en el tiempo y conectados en su filosofía y propuestas, se fundamentaban en la idea explícita de que es posible hacer ciudad desde la propia ciudad, con planteamientos consensuados, y sobre todo desde la base de configuración de una ciudad humanizada y sostenible (Merinero Rodríguez, 2010).

Esta planificación se vio favorecida por el refuerzo de las finanzas municipales destinadas a obras públicas y a proyectos urbanos, en un contexto de expansión de la construcción a escala nacional (Romero, 2012). De este modo, se permitió que, durante casi toda la primera década del siglo XXI, fuera posible llevar a efecto una parte significativa del modelo de ciudad definido en el PGOU (Patiño Rodríguez, 2008).

A continuación se destacan los cinco objetivos clave sobre los que se sustentaba el Plan General y el Plan Estratégico, cuyo desempeño ha influido significativamente en la fisonomía actual de la ciudad. 


\section{III.1. Cambios en el espacio público}

No cabe duda de que la reconsideración de los espacios públicos es uno de los elementos claves y definitorios del nuevo modelo de ciudad descrito en el PGOU y en el Plan Estratégico.

El nuevo PGOU se propuso un cambio de las prioridades urbanas en la competencia del espacio público, un espacio físicamente limitado. La prioridad pasaba a ser del peatón y del tránsito a pié, especialmente en el centro histórico (Ayuntamiento de Sevilla, 2000).

La relación de la sociedad local con la idea de peatonalizar calles importantes comerciales del centro de las ciudades ha sido tradicionalmente conflictiva (Taxiltaris, 2002), también en Sevilla. La principal peatonalización de la anterior década fue la calle Tetuán, por motivos principalmente comerciales, con grupos nacionales e internacionales que querían instalarse y no veían adecuadas las estrechas calles peatonales tradicionales (del Campo Tejedor, 2009), y ello dentro de una agria polémica que duró buena parte de los años 90 . No obstante, el éxito económico de esa operación (se convirtió en la calle comercial de mayor nivel de precios de locales de la ciudad) sirvió de principal elemento demostrativo de los defensores de la rentabilidad económica de generar más espacios peatonales en la ciudad (García García, 2011).

Una de las primeras acciones en llevarse a cabo por el nuevo PGOU en este sentido, y quizás la más radical de ellas, fue la peatonalización de la «avenida ceremonial» del centro de la ciudad que va desde la Plaza Nueva (donde se encuentra el Ayuntamiento), toda la avenida de la Constitución, junto la Catedral, hasta la gran explanada de la Puerta de Jerez y la calle San Fernando, donde se encuentra la antigua fábrica de tabacos, sede de la Universidad de Sevilla.

Siendo el principal acceso al centro histórico, la alternativa para la movilidad se buscó en la implantación de un tranvía a lo largo de todo este espacio (Ayuntamiento de Sevilla, 2005). Sectores de comerciantes y taxistas se opusieron a esta peatonalización por considerarla perjudicial para sus intereses.

El impacto en la imagen de la ciudad, en la mejora de la calidad urbana de espacios que habían pasado a convertirse en estación central de autobuses (Plaza Nueva), o el patrimonio en peligro, como la fachada de la Catedral (junto a la cual transitaban 900 autobuses diarios), fue evidente y notable. Una vez concluidas las obras, la percepción ciudadana fue positiva al respecto, y ello facilitó políticamente la culminación de otras importantes peatonalizaciones en el centro histórico (Alameda de Hércules, sector Alfalfa-Plaza del Salvador), como en otras calles comerciales (San Jacinto, en el barrio de Triana o Asunción, en el barrio de clase media-alta de Los Remedios).

En total se recuperaron como espacios para el peatón 97.900 metros cuadrados (midiendo sólo la superficie de calzada recuperada para el peatón) (Hernández Martínez, 2011). Además, en términos económicos, esta recuperación del espacio público para el peatón supuso una mejora de la actividad económica de la ciudad, al duplicarse en el 2010, las licencias de aperturas de negocios en las zonas peatonales. Por ejemplo, en la Avenida de la Constitución, las licencias se triplicaron desde el año de su peatonalización, 2004. Cabe interpretar, por otra parte, que el espacio peatonalizado ha pasado a ser un espacio muy mercantilizado, y que redunda en una terciarización de la ciudad como mero escaparate y objeto de actividades turísticas y de ocio con, por ejemplo, una extraordinaria proliferación de terrazas de bares (Díaz Parra, 2010). 


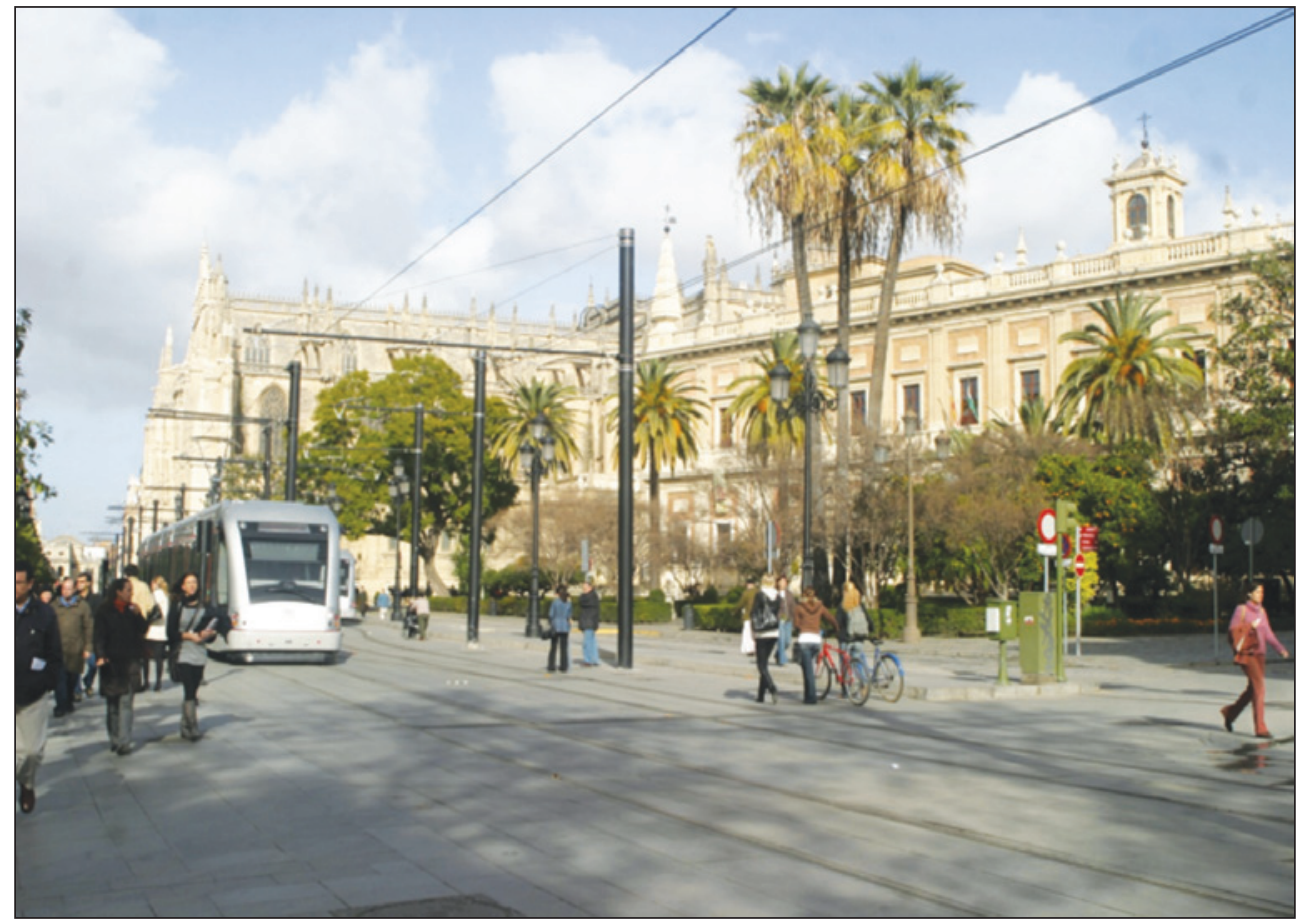

Foto: Juan Ramón Santos.

La renovación de la imagen de la ciudad tiene también como uno de los principales referentes la realización de una obra de arquitectura-espectáculo como es Metropol Parasol del arquitecto Jürgen Mayer, proyecto conocido popularmente como «las Setas» (Webb, 2011) (Shapiro, 2011). Situado en Plaza de la Encarnación, el espacio libre de mayores dimensiones que quedaba en el casco histórico, este espacio integra una pasarela mirador en la planta alta, un mercado de abastos en la planta baja e incluso un enclave arqueológico romano de primer orden en la planta baja.

La creación de este complejo arquitectónico en pleno centro no estuvo exento de polémica ciudadana, por el contraste que suponía con el escenario esperable en una ciudad tradicional como Sevilla, además de por los sobrecostes de la obra. No obstante, cabe decir que actualmente constituye un lugar de gran relevancia urbana y apreciado, que ha obtenido numerosos elogios internacionales. Además, ha servido también para redirigir los flujos comerciales y turísticos hacia el sector norte de la ciudad, históricamente el más depauperado del casco antiguo.

Siguiendo con la apuesta por las transformaciones arquitectónicas de la ciudad, en una parcela propiedad de las Cajas de Ahorros sevillanas en la zona de la isla de la Cartuja más cercana a Triana, el PGOU determinó que debería desarrollarse un proyecto arquitectónico de calidad, señalando implícitamente un rascacielos, dado el coeficiente urbanístico per- 
mitido y la no limitación de altura en la ficha urbanística². La propuesta planteada por los promotores fue efectivamente la construcción de un rascacielos que se convirtiera en otro hito de la ciudad. Tras un concurso de ideas internacional, ganó el proyecto del arquitecto argentino César Pelli. La construcción ha finalizado en 2015. La altura del edificio, la mayor de la región andaluza con 180,5 m, planteó un intenso debate en una ciudad que, como norma no escrita, no había permitido la construcción de edificios más altos que la Giralda. El Comité del Patrimonio de la Humanidad de la UNESCO trató el asunto en su $33^{\text {a }}$ reunión. Finalmente, en 2012, no sin críticas sobre su impacto visual negativo, este organismo internacional evitó la catalogación de los monumentos sevillanos como patrimonio mundial en peligro, como solicitaban organizaciones conservacionistas opuestas al proyecto (UNESCO World Heritage Committee, 2012).

La política destinada a ampliar el espacio público libre y peatonal también incluyó la regeneración de amplias zonas junto al cauce histórico del río Guadalquivir (muelles de Nueva York y Las Delicias), que formaban parte del puerto de Sevilla, pero que con el traslado de éste hacia el sur, río abajo, habían devenido en espacios libres urbanos. También fue objeto de regeneración el cauce histórico en su orilla de la Cartuja, ya que el diseño de la Expo'92 no prestó la atención debida a esta fachada fluvial. Así mismo fue significativa la creación de un anillo de parques urbanos, un total de 9, con una inversión de 190 millones de euros, provenientes en un $75 \%$ de fondos europeos. Con todo ello se consiguió duplicar la actual superficie de parques de Sevilla, pasando de 551 has a 1.129 has.

\section{III.2. Cambios en la movilidad urbana y metropolitana}

La movilidad ha sido siempre una de las principales preocupaciones de la ciudadanía y, por tanto, su mejora se convirtió en uno de los principales desafíos del modelo de ciudad que se estaba propiciando en estos años. Posiblemente estos cambios en la movilidad hayan sido uno de los elementos definitorios y de mayor impacto de los que han contribuido al cambio en el escenario urbano de Sevilla.

Las importantes transformaciones urbanas previas a la Exposición Universal de 1992, antes comentadas, habían significado también importantes inversiones en movilidad, centradas en la mejora de la accesibilidad y fluidez del tránsito de vehículos, con la construcción de vías rápidas, circunvalaciones, puentes sobre el río Guadalquivir y rondas interiores. No obstante, el extraordinario crecimiento del parque automovilístico tuvo como consecuencia que en pocos años, las dificultades circulatorias volvieran a ser las mismas (si no mayores), que antes del desarrollo de la nueva red (Junta de Andalucía, 2006).

El nuevo PGOU vino a presentar un cambio profundo del modelo de movilidad de la ciudad en tres elementos clave. Se pasó de la prioridad del vehículo privado a fomentar el transporte público; de una red fundamentada en el acceso al centro urbano, a una concepción metropolitana de la accesibilidad, integrando en la misma a los municipios adyacen-

2 Ficha ARI-DT-10. Áreas de Reforma Interior en Suelo Urbano No Consolidado. Fichas de Planeamiento y Gestión. PGOU de Sevilla. 2006. «... la determinación de los parámetros de ocupación y altura será adoptados por el PERI sobre la base de una propuesta arquitectónica de calidad.» 
tes; y de un transporte basado en gasoil y gasolina, a un transporte eléctrico ${ }^{3}$ o en bicicleta. Estos objetivos se materializaron principalmente en tres de los símbolos actuales de la movilidad sostenible en Sevilla: la línea 1 del metro, el tranvía y la apuesta por la bicicleta (García García y otros, 2009).

\section{III.2.1. Metro}

El proyecto de movilidad de mayor volumen inversor de este período fue la construcción de la línea 1 del metro de Sevilla. La apuesta de la ciudad por desarrollar un metro data de los años 70. Incluso se inició la construcción de una primera línea, proyecto posteriormente abandonado dado el elevado coste del proyecto (por los suelos arcillosos de la ciudad) y porque la prioridad política en materia de inversiones en Sevilla fue la Exposición Universal de 1992 y los proyectos urbanos relacionados con ella.

A principios de la primera década, se retoma el proyecto de red de metro de Sevilla pero sobre parámetros diferentes. En primer lugar sería el gobierno regional su principal responsable. Además se diseña una red no de carácter urbano, sino metropolitano, para facilitar la articulación de toda la región urbana de Sevilla. Se proyectaron 4 líneas con una longitud total de 52,5 kilómetros y 75 estaciones, en un trazado básicamente subterráneo, con tramos en superficie según los requerimientos técnicos y urbanísticos.

La construcción de la línea 1 se inició 2003, inaugurándose el servicio en abril de 2008. Cuenta con 22 estaciones, una longitud de $18 \mathrm{Km}$., dando servicio a unas 228.000 personas. La media diaria se sitúa en 54.000 usuarios. Además de su contribución a la movilidad, el metro se convirtió en un importante instrumento para revitalizar el comercio en el centro histórico al mejorar el acceso desde los distritos periféricos y localidades metropolitanas (Castillo Manzano, 2009).

Sin embargo, la crisis de las finanzas públicas, derivada de la crisis económica, ha dinamitado los planes previstos para el desarrollo de las restantes líneas de metro, no existiendo actualmente plazo alguno ni previsión para el desarrollo del resto de la red.

\section{III.2.2. Tranvía}

Como ya se mencionó, el acceso a la zona sur del centro urbano comercial, en gran parte peatonalizada, se solucionó mediante la construcción entre 2006 y 2007 de una línea de tranvía con un trayecto de 1,5 kilómetros, con cuatro paradas. Una segunda fase amplió el recorrido en 2011 en otros 880 metros.

\section{III.2.3. Bicicleta}

A partir del año 2005, se apuesta por la construcción en Sevilla de una red de carril bici que durante 2007 llegó a los 77 kilómetros, y en 2010 se amplió hasta 120 kilómetros. La inversión total fue de 30 millones de euros (fig. 7). De manera paralela, se puso en fun-

3 De ser una modalidad inexistente, el transporte colectivo movido por electricidad pasó a transportar al 13\% de los viajeros en la ciudad y su área metropolitana en 2010 (metro=8,4 mill.; tranvía= 4,7 mill.) 
cionamiento un sistema de alquiler de bicicletas públicas gestionado por concesión. Este sistema experimentó un gran crecimiento en poco tiempo, pasando de 3.500 abonados en 2007, a contar con 68.000 abonados en 2010. Se disponen de 2.500 bicicletas distribuidas en 250 estaciones. También se han instalado 5.700 plazas de aparcamiento de bicicletas privadas. El uso de la bicicleta en la ciudad está cuantificado en 70.000 viajes diarios, lo que supone que el $9 \%$ del transporte se realiza en bicicleta.

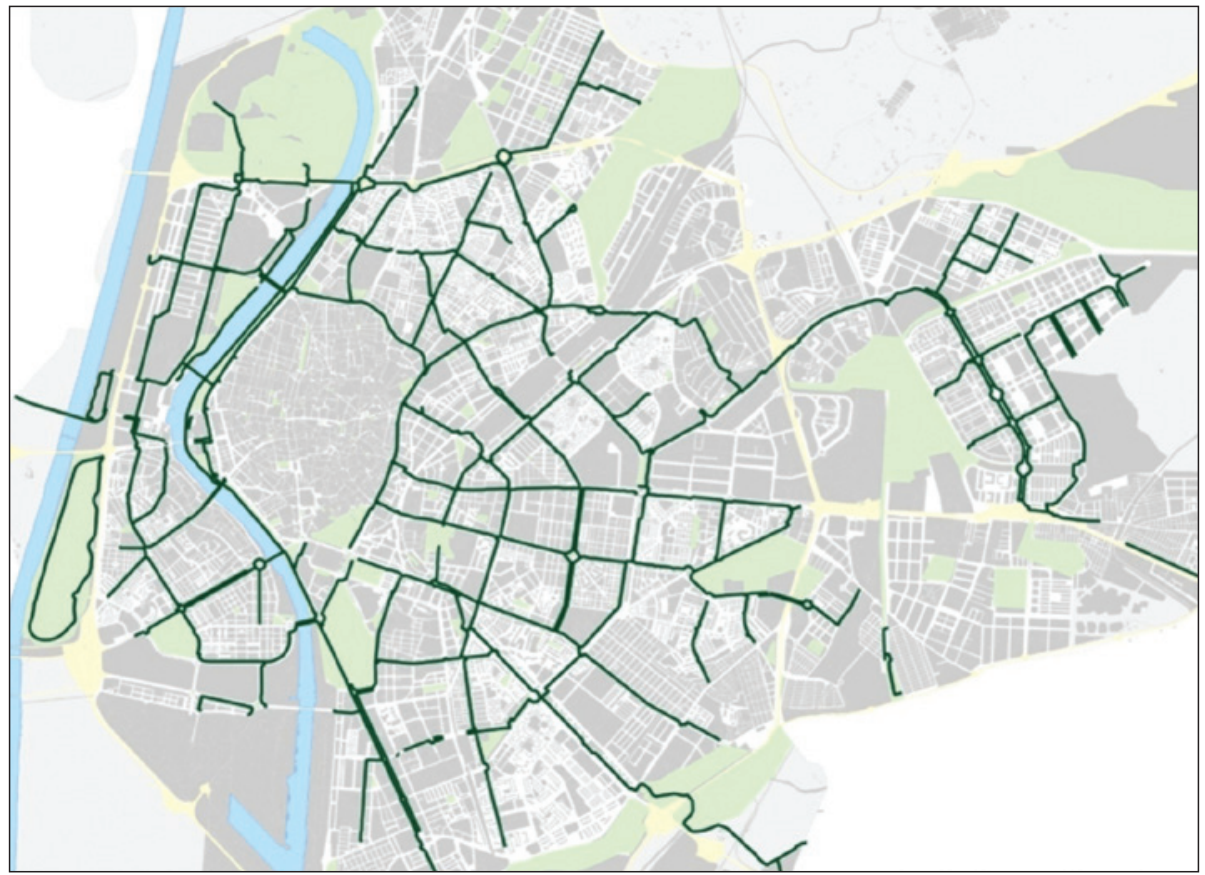

Fuente: elaboración propia a partir de mapa del ayuntamiento de Sevilla.

Todo ello, favorecido por el relieve plano y el clima benigno de la ciudad durante buena parte del año, ha supuesto que Sevilla se haya convertido en la ciudad española que más decididamente ha apostado por este cambio de sistema de transporte, convirtiéndola en un modelo de gran éxito internacional (Castillo Manzano y Sánchez Braza, 2013). Numerosos reconocimientos y elogios internacionales han venido a ratificar esta rotunda apuesta por la movilidad sostenible urbana que ha supuesto un importante cambio de hábitos en la ciudad. Buena prueba de ello es como la ciudad ocupa ahora el puesto 4 en el prestigioso índice internacional Copenhagenize Index 2013 sobre ciudades bicycle friendly (ver http://copenhagenize.eu/index/), sólo por detrás de Amsterdam, Copenhagen y Utrech.

Estas tres importantes contribuciones a la movilidad sostenible no han estado exentas de polémica. El metro recibió críticas en su fase de construcción por los efectos negativos para el comercio local, lo que llevó al gobierno andaluz a elaborar un protocolo de colaboración con 
la asociación de comerciantes para minimizar el impacto negativo en el sector de futuras obras de infraestructuras de transporte. Por otro lado, la implantación del tranvía fue discutida en su momento por la afectación estética de la catenaria junto a la Catedral así como el efecto de la misma en el paso de las cofradías en Semana Santa (del Campo Tejedor, 2009). Avances tecnológicos y nuevos sistemas de baterías, permitieron poco después de su implantación, eliminar el sistema de cables en buena parte del recorrido por la zona monumental (García, 2010).

Por último, la implantación del carril bici en Sevilla sufrió un cierto rechazo en algunas zonas determinadas por eliminar plazas de aparcamiento para los vecinos en calles y avenidas.

\section{III.3. Cambios en el modelo económico}

Superada la crisis post-expo, la ciudad afronta la primera década del siglo XXI participando plenamente del intenso ciclo de crecimiento de la economía nacional. El Plan Estratégico Sevilla 2010 había determinado las acciones para la modernización de la base productiva y del empleo, con especial incidencia en la innovación, la industria aeronáutica, el desarrollo logístico y portuario, y la gestión integral del turismo. También incidió en la necesidad de una concepción funcional y metropolitana del desarrollo económico, tarea en la cual la agencia pública de promoción económica Sevilla Global realizó una labor de análisis, estudio y promoción exterior conjunta de la imagen económica e industrial de la región urbana de Sevilla (Hernández Martínez, y López Izquierdo, 2011b).

La actividad económica de Sevilla se incrementó un 46\% entre los años 2000 y 2007, medida por las actividades sujetas al IAE. Por sectores de actividades económicas, el industrial fue el que experimentó un mayor crecimiento, siendo el dedicado a los servicios, el principal sector de actividad económica.

El PIB per cápita de Sevilla en 2000 era el 74,2\% de la media nacional. Desde 1992 hasta 2000 se había dejado de converger con España. Desde entonces hasta 2005 creció la convergencia con la media nacional a un ritmo sostenido hasta llegar al 81,2\% de la media española (Fig. 8). Incluso varios años Sevilla estuvo a los primeros puestos de España en crecimiento económico. La creación de empleo fue intensa en este período 2000-2008, aumentado en más de un $14 \%$ el número de empleados ${ }^{4}$. La tasa de paro, que era en la ciudad del $18.9 \%$ en 2001, se redujo este período en 6.8 puntos, marcando en 2005 su mínimo histórico en Sevilla con un $10.5 \%$ (Sevilla Global, 2009).

Las bases del crecimiento de Sevilla y su región urbana no se diferencian básicamente de las del resto de España, con un sector de la construcción y auxiliares como motores (Caravaca Barroso y García García, 2009), lo que también explica sus problemas actuales tras el estallido de la burbuja inmobiliaria (Cano Fuentes, 2013), y un sector de servicios y comercial asentado sobre el fuerte crecimiento del consumo en este ciclo de crecimiento.

De forma complementaria se desarrollaron acciones estratégicas destinadas también a mantener e impulsar proyectos industriales y tecnológicos que equilibraran y diversificaran una economía basada fundamentalmente en servicios, administración pública y turismo. Para ello se impulsaron una serie de industrias locales de tradición histórica pero de presente languideciente, como la aeronáutica, la agroalimentaria, o la automovilística.

\footnotetext{
4 datos afiliación a la Seguridad Social.
} 


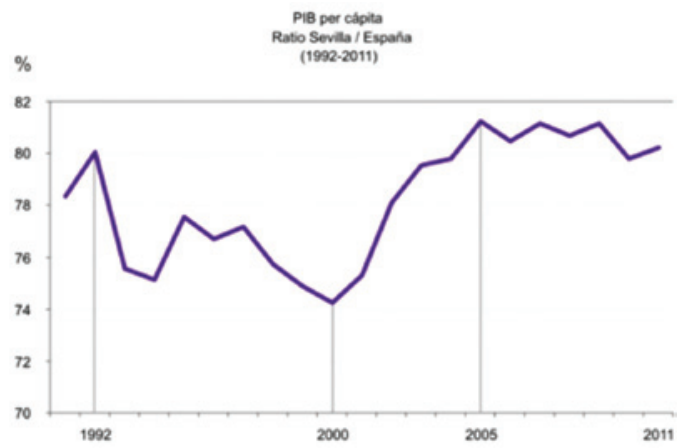

Fuente: INE y elaboración propia.

La visión general de la economía sevillana de esa década debe de completarse haciendo referencia a los años finales de la misma, que estuvieron intensamente marcados por la crisis económica global y nacional. El PIB provincial de Sevilla se redujo en un 3,3\% sólo en 2009. La licitación pública pasó de 1.700 millones de euros en 2008 a 600 en 2010 (-65\%), y la tasa de desempleo pasó del $12,4 \%$ a finales de 2007, al 20,8\% a finales de 2010, con 33.600 parados más en la ciudad (Sevilla Global, 2010). Si bien los datos peores aún estaban por llegar en los primeros años de la siguiente década.

\section{III.3.1. Realización de Grandes Inversiones Productivas Intensivas en Tecnología}

A partir de una industria aeronáutica pre-existente, en 2004 se inicia el proyecto para el ensamblaje final del avión militar AIRBUS 400M, que supuso la creación una nueva factoría de EADS-CASA. El desarrollo en el área metropolitana del parque empresarial Aerópolis, (Parque Tecnológico Aeroespacial de Andalucía), supuso el refuerzo del cluster aeronáutico que pretendía situar a Sevilla entre las ciudades europeas a la vanguardia de esta industria.

Por otra parte la ciudad no se vio tan duramente afectada por la deslocalización de sus principales empresas, como otras. Varias de las más importantes modernizaron sus instalaciones haciéndolas más competitivas desde la perspectiva tecnológica. El papel de colaboración desde lo público fue decisivo en algunos casos, en que el ayuntamiento acordó ventajas urbanísticas y/o traslados dentro del mismo municipio. Este es el caso de las multinacionales: Heinecken - Cruzcampo, Renault - Nissan y Abengoa:

- La construcción y puesta en actividad de la nueva factoría Heinecken - Cruzcampo, iniciada en el año 2005 y finalizada en el 2008, supuso una inversión de 333 millones de euros, y un incremento de la actividad productiva entre 2005 y 2008 de 520,5 millones de euros.

- La planta de Renault y Nissan, que finalizó en el año 2006 las obras iniciadas en el 2004 en la factoría, para dotarla de la capacidad para producir unas 5.500 cajas de cambio de 6 velocidades, cubriendo la mitad del mercado mundial del grupo. 
- El Centro Tecnológico de ABENGOA en Palmas Altas, construido por Richard Rogers, en terrenos que fueron obtenidos por permuta, se inició en el año 2007 y finalizó el año 2009. Es el centro directivo y de investigación principal de esta compañía de origen local y expansión multinacional en el presente.

\section{III.3.2. Desarrollo de nuevos espacios para la innovación tecnológica y productiva}

Los primeros años de funcionamiento del Parque Científico-Tecnológico Cartuja (entonces Cartuja'93), no estuvieron a la altura de las altas expectativas creadas con su creación, sobre todo porque desde la comunicación política se había incidido en las ventajas y grandes perspectivas que abría Cartuja'93, pero se obviaba que este tipo de proyectos necesitan de años de maduración y consolidación. También se vio afectado por la crisis económica unida a otras restricciones en cuanto la posibilidad de adquirir los suelos por parte de las empresas. También desde ámbitos de oposición política, se exageró la imagen de un espacio abandonado para restar valor a las consecuencias positivas de la Exposición Universal de Sevilla, calificada como un dispendio inútil.

Cambios legales para permitir el acceso a la propiedad de las propias parcelas, y un mejor ambiente económico, impulsaron el Parque Científico y Tecnológico de Cartuja desde finales de los 90, hasta convertirlo diez años después en la segunda tecnópolis española en volumen de negocio. En 2010 contaba con un total de 377 empresas y organizaciones, que generaban un empleo directo de 15.065 trabajadores y una actividad económica de 1.912 millones de euros. El PCT Cartuja 93 entre 2000 y 2010 tuvo un aumento de la facturación de un 171\%, y las empresas y organizaciones localizadas en el mismo aumentaron en un 109\%. El 74,6\% de la actividad económica es generada por el sector de las tecnologías avanzadas. En 2006, fruto de un proceso de ampliación tras haberse ocupado los $447.427 \mathrm{~m}^{2}$ iniciales, se le unieron $123.064 \mathrm{~m}^{2}$ correspondientes a zonas colindantes, con los que el recinto pasó a contar con una superficie de $639.419 \mathrm{~m}^{2}$. En octubre de 2010 quedó inaugurada la Tecnoincubadora Marie Curie, un nuevo edificio que alberga 35 empresas de base tecnológica y dos sociedades de apoyo a la creación de empresas.

En esta etapa se desarrollaron también programas de revitalización integral de espacios industriales, orientados a la rehabilitación, y la dotación de nuevos equipamientos y seguridad a los polígonos industriales por importe total unos 13 millones de euros. También se crearon nuevos espacios especializados, como el Parque de Arte Sacro, destinado a las artesanías de función religiosa o tradicional (imaginería, orfebrería,...). Muchas de las empresas situadas en estos espacios industriales de la ciudad expresaron a través de sus organizaciones su insatisfacción por la insuficiencia de estas medidas y la carencia de servicios como transporte público, o una mayor seguridad.

\section{III.3.3. Actividad logística y portuaria}

El Plan Estratégico Sevilla 2010 se trazaba el ambicioso objetivo de convertir a Sevilla en centro de la macro región sur occidental de Europa y centro logístico intermodal de primer nivel. Entendiendo por centro logístico moderno un conjunto de servicios e infraestructuras que garantizaran la organización y distribución intermodal de flujos de mercancías, personas 
e información añadiendo valor a las mercancías en el desarrollo de sus operaciones. Durante la década se pusieron en marcha acciones que apuntaban en esta dirección: configurar Sevilla y su región urbana como el importante «hub» logístico que se planteaba.

La competitividad del Puerto en tráfico de pasajeros no cesó de aumentar desde el año 2003. En el año 2000 el tráfico de pasajeros fue de 3.181, hasta 12.413 en 2010. El tráfico de mercancías sin embargo no conoció apenas variación entre 2000 y 2010, cuando se movieron 4,4 millones de toneladas. Por ello los proyectos portuarios, sin olvidar el tráfico de pasajeros, se orientaron a mejorar la competitividad en el ámbito de las mercancías para que el puerto incidiera en la competitividad económica de la región metropolitana de Sevilla.

Los principales proyectos portuarios de esta etapa fueron: La ampliación del Puerto y mejora de los accesos marítimos, proponiendo un polémico dragado del Guadalquivir hasta su desembocadura (aún sometido a estudio por sus repercusiones ambientales), y mediante la construcción de una nueva esclusa, la nueva Zona de Actividades Logísticas Portuarias de 52 Ha., y el desarrollo de la dársena del Cuarto, en las que se han instalado las primeras terminales polivalentes, que cuentan con dos nuevos muelles, y una zona de actividades logísticas de $29 \mathrm{Ha}$.

\section{III.3.4. Desarrollo del Terciario Avanzado.}

El terciario avanzado, y concretamente los servicios avanzados a la empresa tienen una importancia crucial para la modernización económica del territorio, al permitir la externalización de funciones que tienen un gran impacto en la mejora de la gestión empresarial: comunicación, consultorías especializadas, servicios jurídicos, asesorías, etc. Son importantes para atraer nuevas empresas, y son básicos para la ubicación de sedes de empresas e instituciones cuyo ámbito de actividad sea superior al regional. El crecimiento de este sector en la ciudad de Sevilla ha sido intenso, pasando de entre 100 y 200 empresas en 1997, a 488 en 2008. Sevilla es sin ninguna duda el primer centro andaluz de empresas avanzadas. En 2008 la ciudad de Sevilla concentraba el 24,75\% de las empresas de servicios avanzados de Andalucía, seguida a gran distancia de Málaga con el 12,78\% (Campos Alcaide y García Sánchez, 2009)

\section{III.3.5. Incremento de la actividad turística.}

Otro subsector importante de la economía urbana de Sevilla es el turismo, que supone aproximadamente el 11\% de la economía de la ciudad (Ayuntamiento de Sevilla, 2003). Con más de 3 millones de pernoctaciones anuales (3,3 en 2010), Sevilla es el tercer destino turístico urbano de España, tras Madrid y Barcelona (Medina Molina, C. 2010). Su atractivo monumental y cultural se ha visto reforzado por la renovación urbana y el aumento de la oferta hotelera, que entre 2000 y 2010 creció en un 28\% hasta las 18.000 plazas.

En el año 2005, se aprobó por las administraciones y los agentes sociales implicados en la configuración de Sevilla cómo destino turístico, un plan estratégico del turismo, que posteriormente dio lugar un plan de inversiones turísticas desarrollado entre la Junta de Andalucía y el Ayuntamiento de la ciudad que contó con una inversión de 20 millones de euros para la 
adecuación turística de edificios y espacios singulares. También en este período se realizó la ampliación del Palacio de Congresos y Exposiciones iniciada en el 2008 y que finalizó en 2012, con la creación de un nuevo auditorio.

El propio desarrollo de proyectos urbanos como las peatonalizaciones en el centro histórico, el sistema de alquiler de bicicletas y carril bici, y el espacio Metropol-Parasol («setas» de la Encarnación), han contribuido sin duda a mejorar la imagen y el atractivo de la ciudad, aunque en este sentido se echa en falta estudios de percepción de la demanda que cuantifiquen esta influencia.

\section{III.4. Cambios en el modelo social}

A pesar de este expansivo ciclo económico que se ha expuesto en las anteriores líneas, la ciudad seguía arrastrando en esta primera década del siglo XXI importantes problemas sociales, concentrados en determinadas áreas y que requerían de una solución.

Buena parte de los barrios de clase media y trabajadora quedaron al margen de la renovación urbana de la ciudad generada en la anterior década en torno a la Expo'92, ya que las intensas inversiones en infraestructuras no se equipararon con inversiones en equipamientos en los barrios periféricos.

En el período 2005-2007, con una inversión de más de 108 millones de euros, se llevó a cabo el Plan de Barrios que abarcaba 67 áreas de mejora urbana y de viario repartidas por toda la ciudad. Su objetivo consistía en definir áreas que requerían actuaciones públicas de mejora, conservación y rehabilitación que incluía la renovación de calzadas y pavimentos, la construcción de accesos para personas discapacitadas, la plantación de árboles y la instalación de otros equipamientos como farolas, bancos o parques infantiles.

Sin embargo, el caso más importante de desigualdad, exclusión social y marginalidad de la ciudad se localiza en un conjunto de barrios que forman el sector denominado Polígono Sur. La aplicación durante años de políticas sociales desde una multiplicidad de instituciones y administraciones de forma descoordinada, con un importante gasto público, no había producido efectos satisfactorios (Torres Gutiérrez, 2013).

Desde el gobierno andaluz en coordinación con el ayuntamiento de la ciudad y la delegación del gobierno, se puso en marcha en 2003 el Plan Integral del Polígono Sur, cuya principal novedad consistió en la realización de un plan de manera participada por los habitantes de las zona, y la coordinación de los diferentes servicios y administraciones bajo una figura única denominada Comisionado del Polígono Sur. Esto suponía un cambio profundo en la cultura de la administración, dividida en departamentos funcionales y actuaciones sectoriales difícilmente coordinadas.

Este proceso de participación vecinal y trabajo de técnicos involucrados en la zona, dio como fruto la puesta en marcha de un programa de actuaciones en torno a cuatro áreas de intervención: urbanismo y convivencia, inserción sociolaboral y promoción de la iniciativa económica, intervención socioeducativa y familiar y salud comunitaria. Se ha desarrollado un nuevo modelo de gestión específico para esta zona de la ciudad basado en la coordinación de la acción pública y en la participación ciudadana (Maeztu Gregorio de Tejada y Rosa Caro, 2006).

En este tiempo se han conseguido objetivos de rehabilitación urbanística de espacios públicos y edificios, atención a la infancia y escolarización, y retorno de los servicios públi- 
cos a la zona (transporte, limpieza,...) que antes ni acudían a los enclaves más conflictivos. También un cierto grado de pacificación de la seguridad ciudadana en la zona, si bien la integración y normalización definitiva de determinados núcleos está aún lejos de conseguirse (Comisionado del Polígono Sur, 2013).

Otro de los graves problemas que arrastraba la ciudad era el de la carestía de la vivienda, que estaba produciendo de facto una migración de jóvenes y nuevas familias hacia los municipios del área metropolitana, incapaces de poder acceder a una vivienda en la propia ciudad por el nivel que estaban alcanzando los precios (Martori Canas, 2010). Durante la década de 1990, la promoción pública de viviendas prácticamente había desaparecido (Díaz Parra, 2010). En el periodo 2003-2007 se puso en marcha un programa de construcción de vivienda de promoción pública a un precio tasado muy por debajo del de mercado para dar respuesta a esta demanda social. El Plan Municipal de Vivienda 2003-2007 puso a disposición de promotores públicos y privados el suelo necesario para la construcción de 14.715 viviendas protegidas. De estas viviendas la empresa municipal de vivienda (EMVISESA) construyó y entregó 6.495.

\section{III.5. Cambios en el sistema de valores}

La visión de la evolución de Sevilla en los últimos años no puede completarse sin una aproximación al sistema de valores y la auto imagen comunitaria. El que una ciudad sea capaz de dar el máximo valor añadido a sus recursos tanto para generar dinamismo interno como para atraer flujos externos (capitales, mercancías, conocimientos e información y personas) depende en buena parte de los sistemas de percepciones y creencias que posean la ciudadanía y los actores urbanos sobre la ciudad y sobre sí mismos (Pascual Esteve, 2011). Es esencial que la ciudad se considere una construcción colectiva, y que los actores y la ciudadanía se auto consideren importantes y responsables en dicha construcción.

Las ciencias sociales han mostrado que existen valores como la autosatisfacción, el conservadurismo tecnológico y social, el narcisismo o el nihilismo que son claros enemigos del desarrollo humano porque incapacitan a la ciudadanía a actuar. El sistema de creencias o Ideas, Valores y Actitudes de una ciudad existe e impacta en el progreso y la calidad de vida personal y colectivo y por ello debe ser conocido y reconocido.

Por eso oportuno realizar una aproximación a cómo ha asumido la población local este proceso de cambios. Antes de nada es preciso señalar que la sociedad sevillana ha proyectado una imagen de tradicionalismo, que también es asumida internamente, de apego a la historia y costumbres de la ciudad, que en lo cultural se traduce en una amplísima producción literaria, plástica, musical, centrada en los «temas sevillanos» (Rodríguez Sacristán, 2010). La estructura y contenido de sus celebraciones más conocidas, la Semana Santa y la Feria de Abril, también expresan esa visión enormemente orgullosa, hasta el narcisismo, de la propia identidad. Hay que convenir que como sociedad ha sido capaz de generar o inspirar mitos universales, como Don Juan, o Carmen. Elementos centrales del folclore nacional español, como el flamenco y, en menor medida, las corridas de toros, son expresiones andaluzas capitalizadas en buena parte en Sevilla. Cuando a partir del siglo XVIII y especialmente en el XIX, la España declinante que dejaba atrás un pasado imperial se convertía en un destino preferido para la evocación de los románticos, por exotismo, Andalucía y especialmente Sevilla ocuparon un lugar central de esa construcción mental (Joly, 2001). 
Cabe preguntarse entonces por la dialéctica entre esa cultura tradicionalista y los valores de avance y modernización que se han descrito en los anteriores capítulos. Ello tendría mucho que ver, lógicamente, en la plasmación política de esa cultura. Y aquí ya no está tan claro. Sevilla, ciudad tradicionalista, no es claramente sinónimo de ciudad políticamente conservadora. Históricamente, las primeras décadas del siglo XX y los años de la II República Española (1931-1936), la ciudad era uno de los puntos fuertes de la izquierda democrática y de la izquierda revolucionaria, sobre todo por el componente obrero, vinculado al puerto y las manufacturas. Posteriormente es cierto que la dictadura del general Franco, fuertemente basada en valores católicos tradicionalistas, usó y promovió intensamente las tradiciones de la ciudad en sentido político y de dominio cultural (Moreno Navarro, 1982)

La historia política de la ciudad en el período democrático ha reflejado también esta dicotomía entre valores progresistas y tradicionalistas, destacando el hecho de que Sevilla ha sido durante todo el período un valuarte electoral del PSOE, incluso en los peores momentos electorales socialistas, a escala nacional y regional. No así en el gobierno municipal, donde se han sucedido alcaldes socialistas, regionalistas y conservadores.

Decididamente, en la cartografía mental de la ciudad ocupan un lugar céntrico valores de mantenimiento y conservación de las tradiciones en todos los aspectos. El interesante estudio del catedrático de psiquiatría Jaime Rodríguez Sacristán «La psicología del sevillano», que seguimos en este capítulo, revela que el $85 \%$ de la muestra estudiada en su encuesta se interesa bastante o mucho por mantener las tradiciones de la ciudad. Es un porcentaje abrumadoramente mayoritario, que sin duda debe de recoger todo un espectro más amplio de matices en esa valoración de lo tradicional. No es de extrañar, por tanto, que el debate entre «lo tradicional» versus «lo moderno» sea un tema recurrente que termine marcando toda iniciativa, proyecto o idea que venga en cierto modo a pervertir o degradar la esencia de Sevilla (según unos), o a hacerla avanzar y progresar (según otros), en definitiva, a cambiar el estatus quo preexistente.

Es necesario convenir que en el mundo intelectual y de los generadores de opinión, a través de libros y artículos, han tenido un gran peso los defensores de la subcultura más tradicionalista, que denominaríamos quietista, que se basa en la creencia de que el futuro de la ciudad nunca puede ser mejor de lo que fue en el pasado. Consciente o inconscientemente, esta subcultura busca producir que no se sitúe la modernización de la ciudad como un valor positivo «per se», y que indirectamente se genere desconfianza ciudadana hacia las posibilidades de futuro para Sevilla y la involucración ciudadana en el hacer ciudad que podrían desvirtuar o hacer desaparecer los valores por los que la ciudad de Sevilla es conocida y admirada internacionalmente.

No obstante cabe preguntarse si de esa subcultura del quietismo participa toda la ciudadanía, o si es una subcultura mayoritaria. Y aquí entramos en la consideración de un rasgo de la personalidad del sevillano que es muy aclaratorio: la ambivalencia. La ambivalencia es una características de comunidades de larga historia, que han visto y mantienen memoria antigua de hechos y sucesos, y que por lo general las hace distantes y duales, frecuentemente como mecanismo defensivo, siendo prueba de sentido realista y capacidad de adaptación (Rodríguez Sacristán, 2010).

La celebración de la Exposición Universal de 1992 supuso el punto álgido en esta dialéctica, y un ejemplo de la ambivalencia de la ciudad. En su preparación se generó una enconada 
polémica entre los sectores, que denostaron frecuentemente las transformaciones que se estaban acometiendo y la esencia misma de la celebración que se estaba preparando ${ }^{5}$, y los sectores que la promovían y que en ese momento ocupaban la élite política nacional y andaluza.

La mayor parte de la sociedad asistía como espectadora a la polémica, con la distancia propia de una actitud reservada y ambivalente. No obstante, en aparente contradicción con la frialdad previa al evento, cuando se abrieron las puertas del recinto expositivo la ciudadanía de Sevilla y su región urbana se hizo inmediatamente fan del acontecimiento. Tanto es así que fue reconocido que la escasa afluencia inicial de público exterior se solventó con la reiterada presencia diaria del público local. Cabe decir que la exitosa Expo'92 produjo un efecto importante tanto en el prestigio e incorporación de nuevos valores como el cosmopolitismo, las nuevas tecnologías, la alta cultura, la calidad urbana, la organización, y a su vez un merma en la credibilidad de los mensajes tan críticos contra los proyectos modernizadores que fueron claves en el momento (capacidad para el desarrollo de un proyecto internacional) y posteriormente (tren de alta velocidad, planta hotelera, renovación urbana,...).

El conjunto de proyectos urbanos emprendidos en la siguiente década, también contaron con un eco de intensa oposición mediática y sociopolítica del mismo estilo a lo ocurrido antes de la Expo'92, quizás en menor medida. Como ya se ha comentado, proyectos como la peatonalización, el tranvía, las «Setas» de la Encarnación, la torre Pelli o la red de carriles bici contaron con un rechazo, aunque cada vez más minoritario. Aunque las encuestas reflejan que la mayor parte de la ciudadanía apoyaba los proyectos de renovación urbana, y el nuevo modelo de ciudad (Pascual Acosta, 2011) lo cierto es que no hubo en su desarrollo una estrategia de involucración social exitosa (más allá de las estrategias de comunicación), por parte de los responsables políticos, ni tampoco contaron con activistas en su favor, con la excepción quizás del desarrollo de la red de carril bici.

\section{CONCLUSIONES}

La ciudad de Sevilla en la primera década del siglo XXI fue capaz de aprovechar la positiva coyuntura económica nacional para articular importantes cambios en diferentes dimensiones urbanas clave (movilidad, espacio público, calidad urbana, equipamientos, vivienda o desarrollo económico) que formaban parte articulada de un modelo establecido expresamente en la planificación de los primeros años del siglo: Plan General de Ordenación Urbanística y Plan Estratégico.

Por otra parte las transformaciones urbanas no pueden sino reflejar a su vez transformaciones y cambios en la sociedad que las produce. La renovación del modelo de ciudad se desarrolló con un apoyo social manifestado electoralmente, pero mucho menos expresamente en el momento de acometer los proyectos, merced a la característica ambivalencia y distanciamiento como rasgo mencionado, y que combina actuaciones duales respecto a temas urbanos, propios de una sociedad hasta ahora con componentes predominantes tradicionales y tópicos, pero con evidencias de crecimiento de la influencia de los grupos críticos e independientes, aunque éstos aún carecen de redes y referencias suficientes para hacerse más visibles. (Rodríguez Sacristán, 2010).

\footnotetext{
5 Ver, por ejemplo, «Sufrir el 92», columna de Antonio Burgos en ABC de Sevilla (12-11-88)
} 
La dimensión, continuidad y efecto a medio plazo de esa renovación está actualmente mediatizada y puesta en cuestión por la intensa crisis económica que mantiene a la ciudad con unas altísimas cifras de desempleo, y un bajo pulso económico de todos los sectores excepto del turismo, que sigue presentando unos datos crecientes.

Posiblemente, el actual modelo de ciudad y su extensión y afianzamiento ha ganado prestigio con el paso de los años y parece contar con un apoyo social mayoritario. Al menos lo es en el aspecto político: durante un período de gobierno conservador en la ciudad (20112015) éste no llegó a materializar su intención de reforma del PGOU; por su parte el nuevo gobierno surgido de las urnas en mayo de 2015, que cuenta con el apoyo de la izquierda tradicional (PSOE, IU), y de la izquierda emergente (Participa Sevilla), se fundamenta en un acuerdo que recoge explícitamente «iniciar un proceso de participación y debate para la posible revisión y reprogramación del PGOU siguiendo los mismos principios y modelo de ciudad ${ }^{6} \gg$.

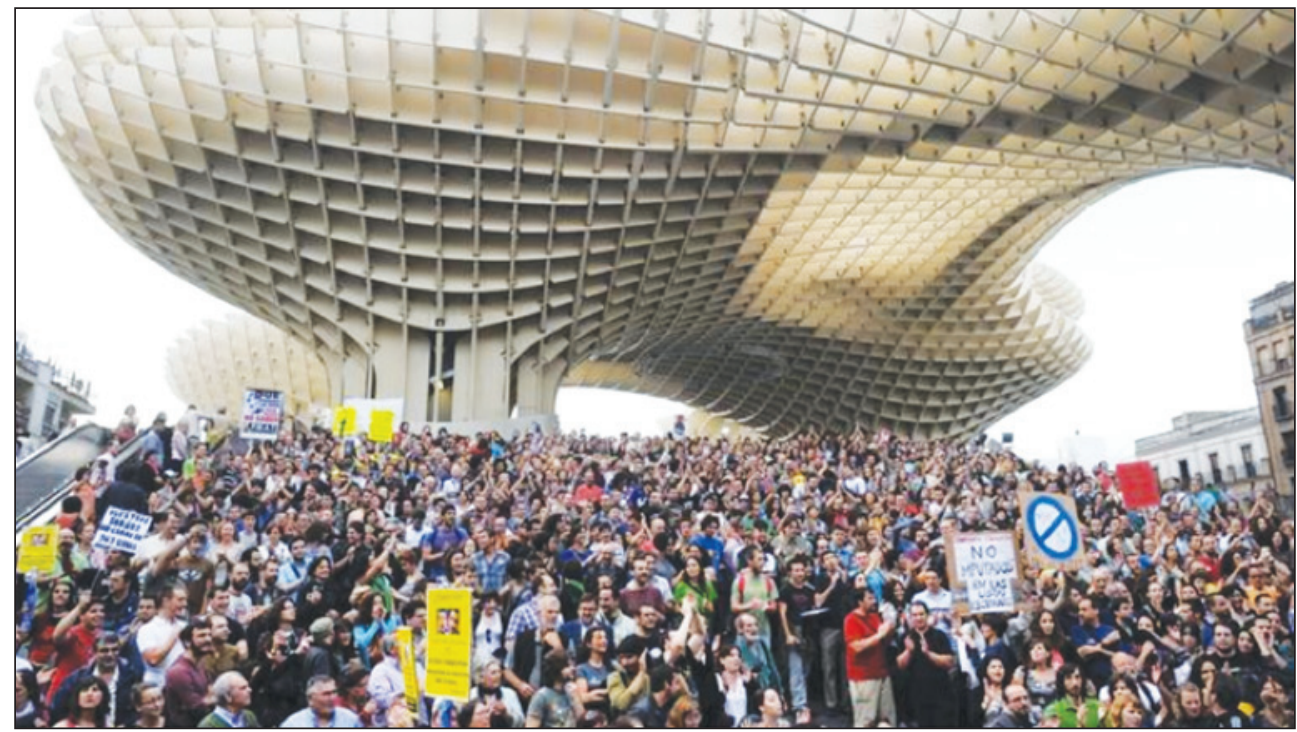

Fuente: Felipe Guzmán, ABC.

Lo que sí cabe pensar es que la pulsión social por participar en la construcción política a todas las escalas es también un hecho a escala urbana, y que posiblemente en los próximos tiempos no se pueda contemplar el desarrollo de procesos de renovación urbana como los emprendidos en la ciudad de Sevilla a finales de los ochenta y en la primera década del siglo, si no es desde la presencia y participación directa de una ciudadanía cada vez más conectada, cada vez más exigente de controlar la gestión pública y cada vez más activa y activista.

6 Documento: «Compromisos asumidos por el PSOE con Participa Sevilla cara a la investidura del Alcalde de Sevilla». 
Tanto PGOU como Plan Estratégico implicaron en su momento procesos participativos en su elaboración, pero fueron procesos participativos que concluían en la presentación final del documento respectivo. Carecieron de mecanismos que aseguraran una apertura permanente al debate y replanteamiento de nuevas aportaciones al modelo de ciudad en el tiempo real de su desarrollo. Proyectos como la Torre Pelli, aún conformes legalidad urbanística fijada en el PGOU, carecieron de fases de debate ciudadano en profundidad, acordes con la intensidad de la transformación paisajística resultante. El reto planteado tanto por las reivindicaciones sociales como por los escenarios políticos que se van conformando consiste en ascender hacia maneras permanentes de corresponsabilidad ciudadana en la gestión de la propia urbe.

Ello sería una buena noticia para el desarrollo de modelos humanistas de ciudad.

\section{BIBLIOGRAFÍA}

ÁLVAREZ REY, L., DOMÍNGUEZ ORTIZ, A., GARCÍA DE CORTÁZAR, F., TUSELL, J., Y FUSI, J. P. (2000): La memoria del siglo XX: Historia de Sevilla. Edit. Diario de Sevilla. AYUNTAMIENTO DE SEVILLA. (2000): Metaplan Sevilla. Gerencia Municipal de Urbanismo.

AYUNTAMIENTO DE SEVILLA (2003): Plan Estratégico Sevilla 2010. Taller de Editores Andaluces.

AYUNTAMIENTO DE SEVILLA (2005): Plan general de ordenación urbanística de Sevilla. Gerencia Municipal de Urbanismo.

CAMPOS ALCAIDE, J. y GARCÍA SÁNCHEZ, F. (2009): «Análisis del Sector Servicios Avanzados a las empresas en la provincia de Sevilla», en Revista Contexto Local, nº13. Sociedad de Estudios Económicos de Andalucía (ESECA). Diputación de Sevilla

CANO FUENTES, G., ETXEZARRETA ETXARRI, A., DOL, K., y HOEKSTRA, J. (2013): «From housing bubble to repossessions: Spain compared to other west european countries». Housing Studies, 28(8), 1197-1217.

CANTERO MARTÍN, P. A., y otros (1999): La ciudad silenciada: Vida social y plan urbano en los barrios del casco antiguo de Sevilla. Ayuntamiento de Sevilla, Área de Participación Ciudadana.

CARAVACA BARROSO, I., y GARCÍA GARCÍA, A. (2009): «The debate over intelligent territories: The case of the metropolitan area of Seville». Eure-Revista Latinoamericana de Estudios Urbano Regionales, 35(105), 23-45.

CARRILLO BENITO, E. (1997): «Local government and strategies for decentralization in the state of the autonomies». Publius-the Journal of Federalism, 27(4), 39-63.

CASTILLO MANZANO, J.I. y LÓPEZ VALPUESTA, L. (2009): «Urban retail fabric and the metro: A complex relationship. Lessons from middle-sized Spanish cities». Cities 26, 141-147.

CASTILLO MANZANO, J.I. y SÁNCHEZ BRAZA, A. (2013): «Managing a Smart bicycle system when demand outstrips supply: The case of the university community in the city of Seville.» Transportation, Vol. 40, N 2, pp. 459-477.

COLLANTES DE TERÁN DELORME, F. y GÓMEZ ESTERN, L. (1999): Arquitectura civil sevillana (3a ed.). Ayuntamiento de Sevilla etc. 
COMISIONADO PARA EL POLÍGONO SUR (Coord.). (2013): Memoria. Plan Integral Polígono Sur 2006-2011. Plan Integral Polígono Sur.

DEL CAMPO TEJEDOR, A. (2009): Proceso de pedestrianization y nueva sociabilidad. Los casos de Sevilla y Málaga. (Fundación Centro de Estudios Andaluces, Ed.) (p. 144).

DÍAZ PARRA, I. (2010): Sevilla, cuestión de clase. Edit. Atrapasueños.

GARCÍA GARCÍA, A. (2011): La calle a escena: El sistema de espacio público de Sevilla y su entorno metropolitano, retos y posibilidades. Ayuntamiento de Sevilla.

GARCÍA GARCÍA, J. y otros (2009): «Study of atmospheric pollution after the implantation of the bike lane in Seville». Gaceta Sanitaria, 23, 291-292.

GARCÍA, P., FERNÁNDEZ, L.M., ANDRÉS GARCÍA, C., y JURADO, F. (2010): «Energy management system of fuel-cell-battery hybrid tramway». IEEE Transactions on Industrial Electronics, 57(12), 4013-4023.

HERNÁNDEZ MARTÍNEZ, E., LÓPEZ IZQUIERDO, A., BETANZOS MARTÍN, J.M., y SANTOS, J.R. (2011): Atlas Sevilla se ve: Actuaciones y proyectos en marcha en la primera década del siglo XXI. Sevilla: Ayuntamiento de Sevilla.

HERNÁNDEZ MARTÍNEZ, E. y LÓPEZ IZQUIERDO, A. (2011b): «Planes estratégicos Sevilla 2010 y 2020», en Territorios Inteligentes: La planificación estratégica en Andalucía, Líberman Grupo Editorial, Jaén. (ISBN 978-84-937-55058).

JUNTA DE ANDALUCÍA (2006): Plan de transporte metropolitano del área de Sevilla. Consejería de Obras Públicas y Transporte. Junta de Andalucía.

LERDO DE TEJADA, J.M. (Coord.) (2004): PGOU de 1987 de Sevilla. Gerencia de Urbanismo. Ayuntamiento de Sevilla.

MAEZTU GREGORIO DE TEJADA, J. y ROSA CARO, M. (2006): Plan integral del Polígono Sur, Sevilla. Ayuntamiento de Sevilla.

MARTORI CANAS, J. C. (2010): «The consequences of the boom of real state sector. Changes in the density in the spanish urban areas, 2001-2007». Scripta Nova, vol. 14 (333)

MEDINA MOLINA, C., REY MORENO, M. y RUFÍN MORENO, R. (2010): «Imagen de los destinos turísticos urbanos y lealtad del turista: ¿Actitud o comportamiento?», Estudios y Perspectivas en Turismo, 19(2), 279-298.

MELERO OCHOA, F. (2005): «La ciudad desbordada. La Sevilla del siglo XX». en La Ciudad y su gente. Historia urbana de Sevilla (García Bernal, J. J. y otros) Edit.: Escuela Libre de Historiadores.

MERINERO RODRÍGUEZ, R. (2010): Manual básico de planificación estratégica urbana y territorial: Elementos básicos para su aplicación en la administración local. Sevilla: Consejería de Gobernación y Justicia.

MORENO NAVARRO, I. (1982): La Semana Santa en Sevilla : conformación, mixtificación y significaciones. Ayuntamiento de Sevilla.

PABLO-ROMERO GIL-DELGADO, M.D.P. (2002): La exposición universal de Sevilla 1992: Efectos sobre el crecimiento económico andaluz. Universidad de Sevilla, Secretariado de Publicaciones.

PASCUAL ACOSTA, A. (Dir.) (2011): Barómetro Socioeconómico Fundación Antares. Sevilla: Centro Andaluz de Prospectiva. 
PATIÑO RODRÍGUEZ, D., ATIENZA MONTERO, P., MIR ÁlVAREZ, L. A., HIERRO RECIO, L. Á., y CARRILLO BENITO, E. (2008): El impacto económico de la planificación urbana: El plan general de ordenación urbanística de Sevilla. Madrid: Civitas.

PASCUAL ESTEVE, J.M. (2011): El papel de la ciudadanía en el auge y decadencia de las ciudades. Valencia: Tirant lo Blanch.

PEREZ ESCOLANO, V. (1998): «Seville at the end of the 20th century, the city's transformation». Cuadernos Hispanoamericanos, (573), 27-37.

ROMERO, J., JIMÉNEZ, F. y VILLORIA, M. (2012): «(Un)sustainable territories: Causes of the speculative bubble in Spain (1996-2010) and its territorial, environmental, and sociopolitical consequences». Environment and Planning C-Government and Policy, 30(3), 467-486.

SEVILLA GLOBAL, AYUNTAMIENTO DE SEVILLA. (2009): Barómetro de economía urbana (19).

SEVILLA GLOBAL, AYUNTAMIENTO DE SEVILLA. (2010): Barómetro de economía urbana (20).

SHAPIRO, G. F. (2011): «Detail Metropol Parasol». Architect, 100(6).

TAXILTARIS, C., BASBAS, S., NIKOLAOU, K., y TZEVELEKIS, I. (2002): «Environmental impact assessment of major pedestrianization schemes through the use of modelling techniques». Fresenius Environmental Bulletin, 11(10A), 800-805.

TORRES GUTIÉRREZ, F.J. (2013): Segregación urbana y exclusión social en Sevilla: el paradigma Polígono Sur. Fundación Focus-Abengoa.

UNESCO WORLD HERITAGE COMMITTEE (2012): «Convention concerning the protection of the world cultural and natural heritage» Report of decisions. $36^{\mathrm{a}}$ session (Saint Petersburg, Russian Federation). (http://whc.unesco.org/archive/2012/whc12-36com19e.pdf) Accessed 27.04.14.

VEGARA, A., RIVAS, J.L.D.L. y LERNER, J. (2004): Territorios inteligentes: Nuevos horizontes del urbanismo. Madrid: Fundación Metrópoli.

WEBB, M. (2011): «Metropol Parasol Location Seville, Spain». Architectural Review, 229(1372), 58-63. 
